\title{
Can perioperative hemodilution be monitored with non-invasive measurement of blood hemoglobin?
}

\author{
Robert G. Hahn ${ }^{1 *}$ D, Patrick Y. Wuethrich ${ }^{2}$ and Joachim H. Zdolsek ${ }^{3}$
}

\begin{abstract}
Background: Trends in non-invasive measurements of blood hemoglobin $(\mathrm{Hb})$ may be useful for identifying the need for transfusion in the perioperative period.

Methods: Crystalloid fluid $(5-20 \mathrm{~mL} / \mathrm{kg})$ was administered intravenously or by mouth to 30 volunteers and 33 surgical patients in five non-randomized clinical studies where Hb was measured on 915 occasions by non-invasive (Radical- $7^{\mathrm{TM}}$ ) and invasive methodology. The hemodilution curves were compared by volume kinetic analysis and linear regression, with the slope and scattering of the data as key outcome measures.

Results: The slope was 1.0, indicating unity between the two modes of measuring $\mathrm{Hb}$ when crystalloid fluid was infused in volunteers; however, only $40-45 \%$ of the variability in the non-invasive $\mathrm{Hb}$ could be explained by the invasive $\mathrm{Hb}$. Patients undergoing major surgery, who showed the most pronounced hemodilution (median $24 \mathrm{~g} / \mathrm{L}$ ); non-invasive $\mathrm{Hb}$ explained $72 \%$ of the variability but indicated only half the magnitude of the invasive $\mathrm{Hb}$ changes (slope $0.48, P<0.001$ versus the volunteers). Simulations based on volume kinetic parameters from the volunteers showed $25 \%$ less plasma volume expansion after infusion when based on non-invasive as compared to invasive $\mathrm{Hb}$, while no difference was found during infusion.
\end{abstract}

Conclusions: In volunteers the non-invasive Hb had good accuracy (low bias) but poor precision. In surgical patients the non-invasive $\mathrm{Hb}$ had good precision but systematically underestimated the hemodilution. Despite severe limitations, the non-invasive technology can be used to follow Hb trends during surgery if supported by occasional invasive measurements to assure acceptable quality of the hemodilution curve.

Trial registrations: ControlledTrials.gov NCT01195025, NCT01062776, NCT01458678, NCT03848507, and NCT01360333 on September 3, 2010, February 4, 2010, October 25, 2011, February 20, 2019, and May 25, 2011, respectively.

Keywords: Pulse oximetry, Hemoglobin, Non-invasive measurement, Point of care tests

\footnotetext{
* Correspondence: r.hahn@telia.com; robert.hahn@ki.se

${ }^{1}$ Research Unit, Södertälje Hospital, Södertälje, and Karolinska Institutet at Danderyds Hospital (KIDS), Stockholm, Sweden

Full list of author information is available at the end of the article
} 


\section{Background}

The measurement of the blood hemoglobin $(\mathrm{Hb})$ concentration is a guide that determines when transfusion of erythrocytes should be initiated. Sporadic measurement of $\mathrm{Hb}$ is often performed during major surgery to evaluate when the $\mathrm{Hb}$ value corresponding to the "transfusion trigger" is reached. Continuous measurement of $\mathrm{Hb}$ would therefore be of substantial value to refine these decisions. For this purpose, non-invasive $\mathrm{Hb}$ analysis has been commercially available for about a decade in the form of the multi-wavelength pulse oximeter Radical- $7^{\text {TM }}$ from Masimo Inc.

Many studies have performed point-wise comparisons between non-invasive and invasive $\mathrm{Hb}$ [1-13], and the main problem with the non-invasive technology is its poor precision. Several studies show good accuracy but $95 \%$ limits of agreement with a range of $40 \mathrm{~g} / \mathrm{L}$ or more [3-9], which makes non-invasive $\mathrm{Hb}$ measurements difficult to rely on.

A more essential clinical question is whether the changes in $\mathrm{Hb}$ agree over time in an individual patient. If this is the case, the pulse oximeter could be calibrated with the known invasive $\mathrm{Hb}$ when surgery starts and then be used to indicate relative changes. To study this possibility, we reviewed the linearity between changes in $\mathrm{Hb}$ level as given by non-invasive and invasive $\mathrm{Hb}$ monitoring, using data from five cohorts where the $\mathrm{Hb}$ level had shifted due to fluid therapy and/or hemorrhage.

The aim of the present report was to determine the reliability of the non-invasive $\mathrm{Hb}$ for tracking changes in invasive $\mathrm{Hb}$. Our hypothesis was that the non-invasive alternative is a useful index of $\mathrm{Hb}$ changes. This issue was studied by direct comparisons of $\mathrm{Hb}$ trends and also by assessing kinetic analyses of plasma volume shifts based on either mode of $\mathrm{Hb}$ measurement.

\section{Methods}

Data from five case non-randomized clinical trials where the $\mathrm{Hb}$ concentration was altered by intravenous or oral administration of crystalloid fluid with and without hemorrhage was reviewed. All studies were approved by the appropriate local Ethics committee and were registered at ClinicalTrials.gov before any patient was recruited. This report adheres to the CONSORT guidelines.

\section{Procedures}

The five series comprised only euhydrated subjects.

Study 1 included the infusions of $25 \mathrm{~mL} \mathrm{~kg}^{-1}$ of Ringer's solution given 10 healthy male volunteers [11]. Study 2 evaluated the ability of volume kinetics to detect deliberately induced dehydration; here, only the
10 control infusions of $10 \mathrm{~mL} \mathrm{~kg}^{-1}$ of Ringer's were used [12].

Study 3 used repeated $\mathrm{Hb}$ sampling during a short infusion of $5 \mathrm{~mL} \mathrm{~kg}^{-1}$ of Ringer's in the morning before surgery; the cohort originally included 30 patients, but only 10 of them were randomly selected for inclusion in the present study to maintain balance between volunteers and surgical patients [13].

Study 4 included 23 patients who underwent open radical cystectomy and urinary diversion under general anesthesia combined with thoracic epidural analgesia. Baseline fluid maintenance of $1 \mathrm{~mL} \mathrm{~kg}^{-1} \mathrm{~h}^{-1}$ of Ringer's until the end of the removal of the bladder and thereafter increased to $3 \mathrm{~mL} \mathrm{~kg}^{-1} \mathrm{~h}^{-1}$ of Ringer's until the end of surgery. A fixed dose of $20 \%$ albumin solution ( $3 \mathrm{~mL} \mathrm{~kg}^{-1}$; Albumin CSL 20\%, CSL Behring, Bern, Switzerland) was given over 30 min until removal of the bladder (expected blood loss of $>500 \mathrm{~mL}$ ) was started. Blood loss was replaced with the Ringer solution in a 1:1 ratio. A supportive administration of norepinephrine, starting at a rate of starting at $30 \mathrm{ng}$ $\mathrm{kg}^{-1} \min ^{-1}$ (to maintain the mean arterial blood pressure at $>65 \mathrm{mmHg}$ ) and mini fluid challenges of $100 \mathrm{~mL}$ of Ringer's (to maintain the hemodynamics pulse pressure variation $>10$ ), until normovolemia was restored [14]. One unit of erythrocytes was transfused, but this was administered after data collection had been completed.

Study 5 comprised healthy volunteers who ingested $500 \mathrm{~mL}$ of isotonic saline by mouth [15].

Table 1 shows the details and characteristics of the five cohorts, which have been published with other study questions. Precise inclusion and exclusion criteria were given for the respective studies [11-15], but subjects with clinically apparent hemodynamic, hepatic, renal, or pulmonary impairment were not included in any of them.

Repeated non-invasive measurements of $\mathrm{Hb}$ and the perfusion index in the hand were obtained from a pulse oximeter (Radical 7, Masimo Corp., Irvine, CA). At the same points in time, a blood sample was obtained for later measurement of the $\mathrm{Hb}$ concentration at the hospital's official chemical laboratory with a coefficient of variation of approximately $1.0 \%$. Blood gas machines were not used.

\section{Linear relationships}

Linear relationships were evaluated by comparing noninvasive and invasive $\mathrm{Hb}$ on a regression plot. The scatter was used as the measure of precision and expressed as the coefficient of determination $\left(\mathrm{r}^{2}\right)$ of the regression line. The coefficient of determination is the fraction of the variability of $y$ (non-invasive $\mathrm{Hb}$ ) that can be explained by $\mathrm{x}$ (invasive $\mathrm{Hb}$ ). A high $\mathrm{r}^{2}$ is desirable, as it 
Table 1 Demographics and characteristics of the studied patient groups

\begin{tabular}{|c|c|c|c|c|c|}
\hline & Study 1 & Study 2 & Study 3 & Study 4 & Study 5 \\
\hline Subjects & Volunteers & Volunteers & Before major surgery & During open cystectomy & Volunteers \\
\hline N & 10 & 10 & 10 & 23 & 10 \\
\hline Males / females & $10 / 0$ & $10 / 0$ & $7 / 3$ & $19 / 4$ & $7 / 3$ \\
\hline Age, years & $22(18-28)$ & $22(19-37)$ & $64(29-82)$ & $69(67-75)$ & $33(10)$ \\
\hline Body weight, kg & $79(65-101)$ & $80(75-100)$ & $79(70-87)$ & $87(64-90)$ & $77(13)$ \\
\hline Infused & Ringer's acetate & Ringer's acetate & Ringer's acetate & $\begin{array}{l}20 \% \text { albumin + } \\
\text { Ringer's lactate }\end{array}$ & Isotonic saline \\
\hline Amount, time & $20 \mathrm{~mL} / \mathrm{kg}$ & $10 \mathrm{ml} / \mathrm{kg}$ & $5 \mathrm{~mL} / \mathrm{kg}$ & $3 \mathrm{~mL} / \mathrm{kg}+2100 \mathrm{~mL}$ & $500 \mathrm{~mL}$ \\
\hline Infusion time (min) & 30 & 20 & 15 & 300 & $2-3 \min$ \\
\hline Hemorrhage (mL) & 0 & 0 & 0 & $950(700-1225)$ & 0 \\
\hline Sampling points (N) & 25 & 16 & 9 & 14 & 10 \\
\hline Duration (min) & 180 & 120 & 70 & 300 & 120 \\
\hline Reference & 11,16 & 2,12 & 13 & 14 & 15 \\
\hline Ethics approval, city & Stockholm, SE & Linköping, SE & Linköping, SE & Bern, CH & Linköping SE \\
\hline Ethics approval, Nr & 2009/1091-31/2 & M114-09 & 2011/101-31 & 2018-02351 & 2010/241-31 \\
\hline ClinicalTrials.gov & NCT01195025 & NCT01062776 & NCT01458678 & NCT03848507 & NCT01360333 \\
\hline
\end{tabular}

implies that data scattering around the regression line is small.

Whether the non-invasive decreases as much as the invasive $\mathrm{Hb}$ during hemodilution is a different issue. We use the slope, i.e. the steepness, of the regression line between these two variables to express the accuracy of a series of non-invasive measurements in the same subject. A slope lower than 1.0 means that the numerical change in non-invasive $\mathrm{Hb}$ is less than that for the invasive $\mathrm{Hb}$. Values higher than 1.0 denote the opposite relationship.

\section{Volume kinetics}

The kinetics of the infusion fluid was studied by a mixed model approach on the non-invasive and invasive data separately. The first three were included while the fourth was excluded due to the large hemorrhage (median 950 $\mathrm{mL}$ ) and the use of two infusion fluids. The fifth was also excluded because the oral ingestion of fluid would necessitate the use of a structurally different kinetic model than was used for the other studies.

The model had two dependent variables, the total urinary excretion and frequently measured plasma dilution. The latter was derived as the hemodilution divided by (1-baseline hematocrit). In turn, the hemodilution had been obtained as $\left(\mathrm{Hb}_{\mathrm{o}}-\mathrm{Hb}\right) / \mathrm{Hb}$, in which $\mathrm{Hb}_{\mathrm{o}}$ is the baseline value and $\mathrm{Hb}$ denotes measurements taken at a later time.

The model has been created to reflect body physiology. $V_{\mathrm{c}}$ is thought to correspond to the plasma from which distribution and redistribution occurs to an extravascular space, $V_{\mathrm{t}}$. Hence, a two-volume kinetic model with rate constants for distribution and re-distribution $\left(k_{12}\right.$ and $\left.k_{21}\right)$, one route of elimination $\left(k_{10}\right)$, and one scaling factor between dilution and volume $\left(V_{\mathrm{c}}\right.$, central volume) was fitted to two dependent variables in all experiments on a single occasion, using the Phoenix software for nonlinear mixed effects, version 1.3 (NLME, Pharsight, St. Louis, MO). All flows are proportional to the value of the rate constant to the volume expansion of a fluid space, being $V_{\mathrm{c}}$ for $k_{12}$ and $k_{10}$, and $V_{\mathrm{t}}$ for $k_{21}$. The estimate of $k_{10}$ was stabilized by the measured urinary excretion, as described elsewhere [11-13]. The search routine used was the First-Order Conditional Estimation Extended Least Squares (FOCE ELS).

\section{Statistics}

Data are reported as the median (25th to 75th percentile) and kinetic parameters as the best estimate and 95\% confidence interval. The agreement between the two modes of measuring $\mathrm{Hb}$ was illustrated by Bland-Altman plots that showed the mean difference (the agreement) and the associated 95\% limits of agreement (i.e., \pm 2 standard deviations of the differences). Point-wise comparisons been non-invasive and invasive $\mathrm{Hb}$ measurements has previously been reported from three of the five case series [11-13].

Relationships were studied by simple linear regression, where $r^{2}=$ the coefficient of determination (the "scatter" of the data).

The number of experiments was set at 60, which was felt to be an appropriate number for outlining the relationship between non-invasive and invasive $\mathrm{Hb}$. Power analysis was applied in the respective studies. $P<0.05$ was statistically significant. 

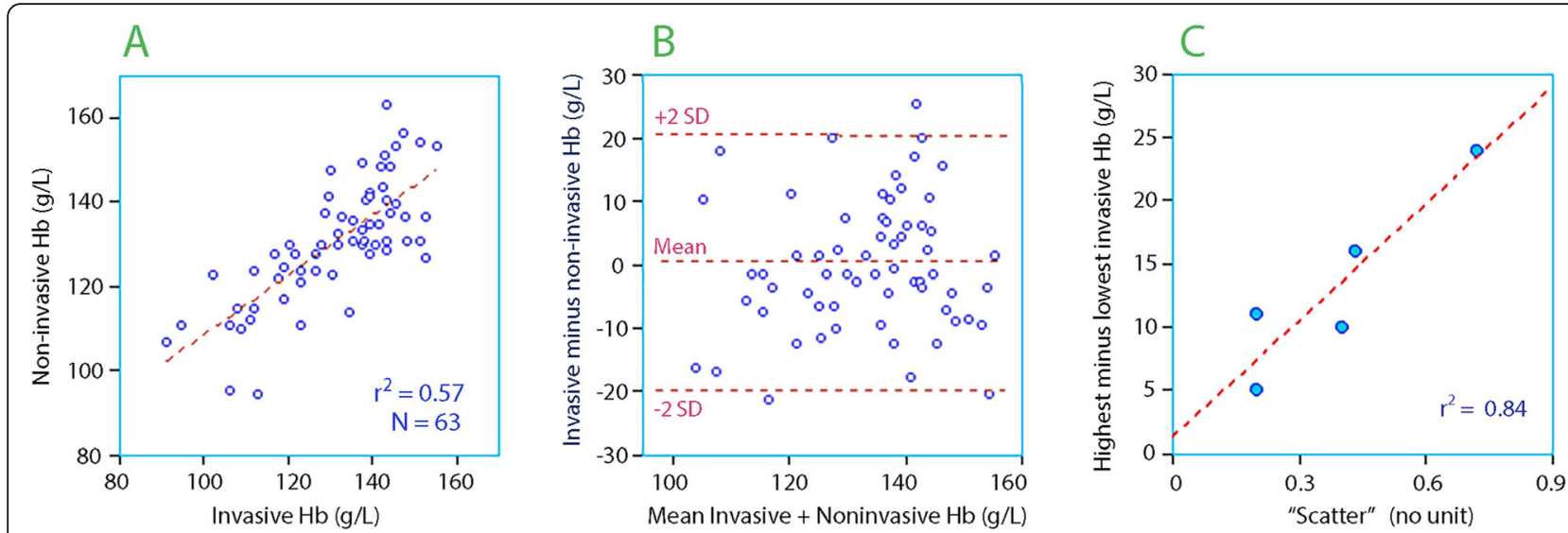

Fig. 1 a The invasive versus non-invasive $\mathrm{Hb}$ concentration at the onset of the infusions. $\mathbf{b}$ Bland-Altman plot of the data shown in the previous subplot. c Relationship between the median "scatter" around the regression lines for each of the five groups, i.e. the coefficient of determination

\section{Results}

At baseline, a statistically significant correlation was observed between the invasive and non-invasive measurement of $\mathrm{Hb}$ (Fig. 1a). The mean difference was only + $0.5 \mathrm{~g} \mathrm{~L}^{-1}$, but the $95 \%$ limits of agreement ranged from -20 to +21 g/L (Fig. 1b).

\section{Maximum and minimum $\mathrm{Hb}$}

The highest invasive $\mathrm{Hb}$ measured in the 63 patients was 136 (121-144) g L $\mathrm{L}^{-1}$ and the lowest 117 (107-130) $\mathrm{g} \mathrm{L}^{-1}$. For the non-invasive $\mathrm{Hb}$, these values were 131 (123-141) $\mathrm{g} \mathrm{L}^{-1}$ and 117 (105-126) $\mathrm{g} \mathrm{L}^{-1}$, respectively
(Table 2). The difference between highest and lowest was quite similar for the two modes of measuring $\mathrm{Hb}$, at $14(10-21)$ vs. $15(11-20) \mathrm{g} \mathrm{L}^{-1}$. Hb was $\leq 100 \mathrm{~g} \mathrm{~L}^{-1}$ in 90 of the 915 invasive measurements (10\%).

In the subsequent presentation, we refrain from making point-wise comparison between the two technologies but focus on the linearity between their relative changes in a series of measurements in the same subject when $\mathrm{Hb}$ is deliberately changed. The results are expressed as the scatter (precision) and slope (accuracy) of non-invasive $\mathrm{Hb}$ to indicate the invasive $\mathrm{Hb}$.

Table 2 Comparisons between non-invasive and invasive $\mathrm{Hb}$

\begin{tabular}{|c|c|c|c|c|c|}
\hline & Study 1 & Study 2 & Study 3 & Study 4 & Study 5 \\
\hline \multicolumn{6}{|l|}{ Invasive $\mathrm{Hb}$} \\
\hline Highest Hb (g/L) & $144(142-145)$ & $138(132-144)$ & $123(113-136)$ & 129 (116-140) & 138 (132-149) \\
\hline Lowest Hb (g/L) & $127(124-130)$ & $128(122-134)$ & $114(104-121)$ & $107(97-113)$ & $134(126-136)$ \\
\hline Highest - lowest Hb (g/L) & $16(16-19)$ & $10(9-11)$ & $11(9-14)$ & $24(16-28)$ & $5(5-6)$ \\
\hline Maximum change (\%) & $13(13-15)$ & $8(7-9)$ & $10(7-12)$ & $22(14-27)$ & $4(3-5)$ \\
\hline Patient mean dilution (\%) & $7.0(5.2-7.8)$ & $3.9(2.9-5.4)$ & $4.2(3.4-6.7)$ & $11.5(6.7-14.3)$ & $2.9(1.4-2.7)$ \\
\hline \multicolumn{6}{|l|}{ Non-invasive Hb } \\
\hline Highest SpHb (g/L) & 139 (131-149) & $134(130-141)$ & $126(111-137)$ & $123(117-136)$ & $134(130-150)$ \\
\hline Lowest SpHb (g/L) & $118(109-126)$ & $117(111-122)$ & $108(99-120)$ & $112(96-124)$ & $126(123-139)$ \\
\hline Perfusion index (\%) & $5.2(3.0-7.5)$ & $7.9(5.7-8.9)$ & $5.0(2.5-5.7)$ & $3.2(2.1-3.5)$ & $4.1(2.6-6.4)$ \\
\hline Highest - lowest Hb (g/L) & $21(19-25)$ & $19(14-20)$ & $15(11-19)$ & $13(7-23)$ & $10(8-11)$ \\
\hline Maximum change (\%)) & $17(15-24)$ & $15(12-18)$ & $13(9-16)$ & $11(6-21)$ & $8(7-8)$ \\
\hline Patient mean dilution (\%) & $8.6(6.5-10.8)$ & $5.3(2.0-7.8)$ & $2.4(0.4-5.2)$ & $4.3(3.5-8.9)$ & $0.2((-0.8)-0.7)$ \\
\hline \multicolumn{6}{|l|}{ Comparisons } \\
\hline Scatter $\left(r^{2}\right) \mathrm{Hb}$ values & $0.43(0.22-0.61)$ & $0.40(0.25-0.63)$ & $0.20(0.05-0.44)$ & $0.72(0.48-0.81)$ & $0.20(0.07-0.37)$ \\
\hline Slope $\mathrm{Hb}$ values & $0.95(0.79-1.12)$ & $1.04(0.90-1.39)$ & $0.46(0.37-0.77)$ & $0.49(0.36-0.72)$ & $0.16((-0.72)-0.70)$ \\
\hline Slope Hb dilution & $0.96(0.75-1.14)$ & $1.06(0.72-1.73)$ & $0.43(0.32-0.78)$ & $0.38(0.29-0.81)$ & $0.16((-0.72)-0.49)$ \\
\hline Difference $\mathrm{Hb}$ dilution Invasive - non-invasive & $-1.1((-3.6)-0.2)$ & $-1.1((3.4)-1.9)$ & $1.2((-0.1)-6.0)$ & $6.0(2.4-9.7)$ & $1.6((-0.1)-3.6)$ \\
\hline
\end{tabular}




\section{Scattering}

Overall, 46 (22-72)\% of the changes of non-invasive $\mathrm{Hb}$ could be explained by changes in invasive $\mathrm{Hb}$, i.e. the median "scatter" $\left(r^{2}\right)$ was 0.46 . However, variability between the studies was considerable; the data were most closely assembled around the regression line during major surgery, $\mathrm{r}^{2}$ being 0.72 (Table 2).

As a rule, the scatter decreased with the $\mathrm{Hb}$ range in each series; a greater difference between the highest and lowest invasive $\mathrm{Hb}$ led to a higher $\mathrm{r}^{2}$ for the relationship between the two variables (Fig. 1c).

\section{Slope}

The regression slope shows how much of a change in invasive $\mathrm{Hb}$ is indicated by non-invasive $\mathrm{Hb}$ on the average during an entire experiment. The non-invasive $\mathrm{Hb}$ could either underestimate (weak slope, $<1.0$ ), predict well (good slope $=1.0$ ), or overestimate (steep slope, $>1.0$ ), respectively, the hemodilution given by the invasive $\mathrm{Hb}$. Figure 2 shows three individual experiments where the slope factor for the regression was weak, good, and steep.

Overall, the slope factor was $0.57(0.33-1.01)$ but it differed greatly depending on the presence of surgical stress, being $1.00(0.80-1.14)$ in the volunteer studies and $0.48(0.37-0.73)$ in in association with surgical stress (studies 3 and $4 ; P<0.006$ ).

In Study 4, the surgical hemorrhage volume was 950 (780-1225) $\mathrm{mL}$ and did not correlate with the data scattering or with the slope factor.

\section{Hemodilution}

Figure 3 compares all invasive and non-invasive hemodilution measurements in each sub-study. The patient mean hemodilution was $6.0(3.5-10.3) \%$ for the invasive and $4.9(1.3-8.0) \%$ for the non-invasive technologies $(P<0.01)$.

The non-invasive $\mathrm{Hb}$ underestimated the hemodilution given by the invasive $\mathrm{Hb}$ in the surgical stress studies, but not the volunteer studies; the difference between the patient mean hemodilution, as given by invasive and non-invasive $\mathrm{Hb}$, was $-0.1(-2.4$ to +2.5$) \%$ in the volunteer studies but $+4.2(1.0-8.3) \%$ in the studies associated with surgical stress $(P<0.001)$.

Figure 4a compares, in each subject, the relationship between the mean hemodilution as given by invasive and non-invasive $\mathrm{Hb}$.

Figure $4 \mathrm{~b}$ shows the distribution of subjects between ranges of slope factors.

\section{Low perfusion index}

Only 15 of the 915 points of measurement (1.6\%) were performed in the presence of a perfusion index of 1.0 or lower, and these low values occasionally distorted the data in Study 1 and 4 (Fig. 3f, Fig. 5).

\section{Volume kinetics}

Fitting the two-volume kinetic model to the data on plasma dilution and urinary excretion was successful for both the invasive and the non-invasive methods (Fig. 6ac). The precision of the kinetic parameters was higher for the invasive $\mathrm{Hb}$ than for the non-invasive $\mathrm{Hb}$ (Table 3), and more outliers became apparent when the kinetic parameters were used to re-create the dependent variables (Fig. 6d and e).

The best estimates of all parameters, as shown in Table 3, were used to simulate the outcome of fictious infusions. Those plots showed that the simulated expansion of the plasma volume was smaller when the noninvasive $\mathrm{Hb}$ was used - a difference that can be
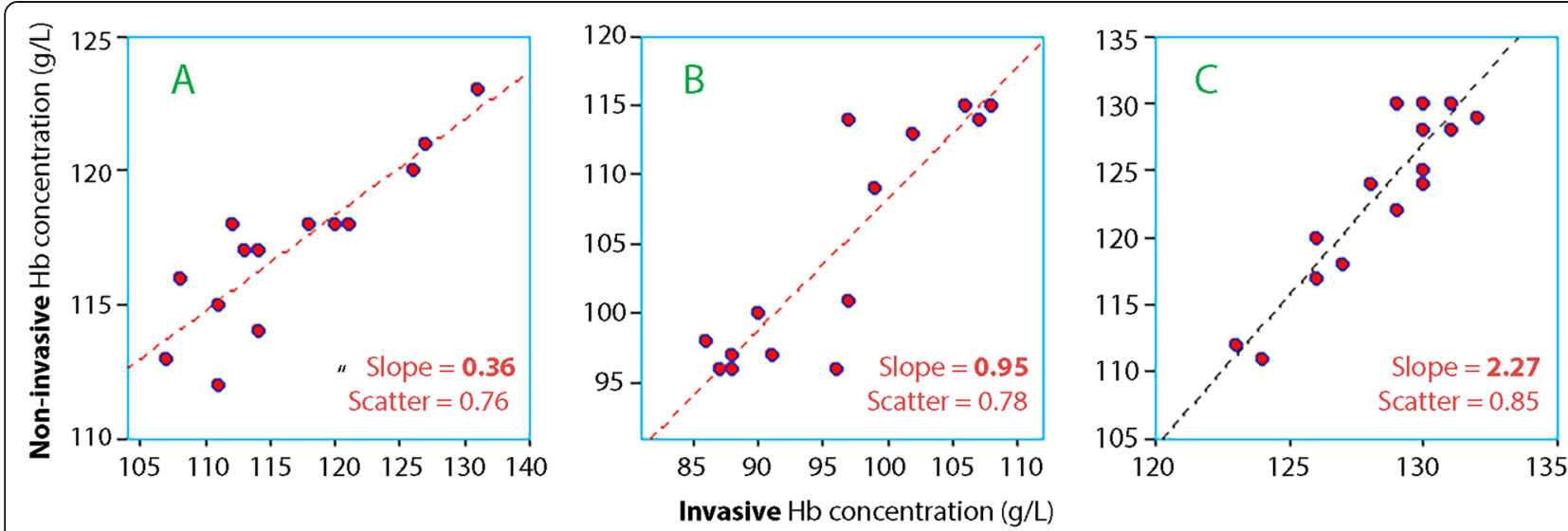

Fig. 2 Three experiments with different slopes. Distances between the marks are set equal in each subplot to facilitate comparison. a Flat slope. The non-invasive $\mathrm{Hb}$ changes much less than the invasive $\mathrm{Hb}$. $\mathbf{b}$ Normal slope. The rise in non-invasive Hb is similar to the rise of the invasive $\mathrm{Hb}$. c Steep slope. Greater increase in non-invasive $\mathrm{Hb}$ than for the invasive technology 

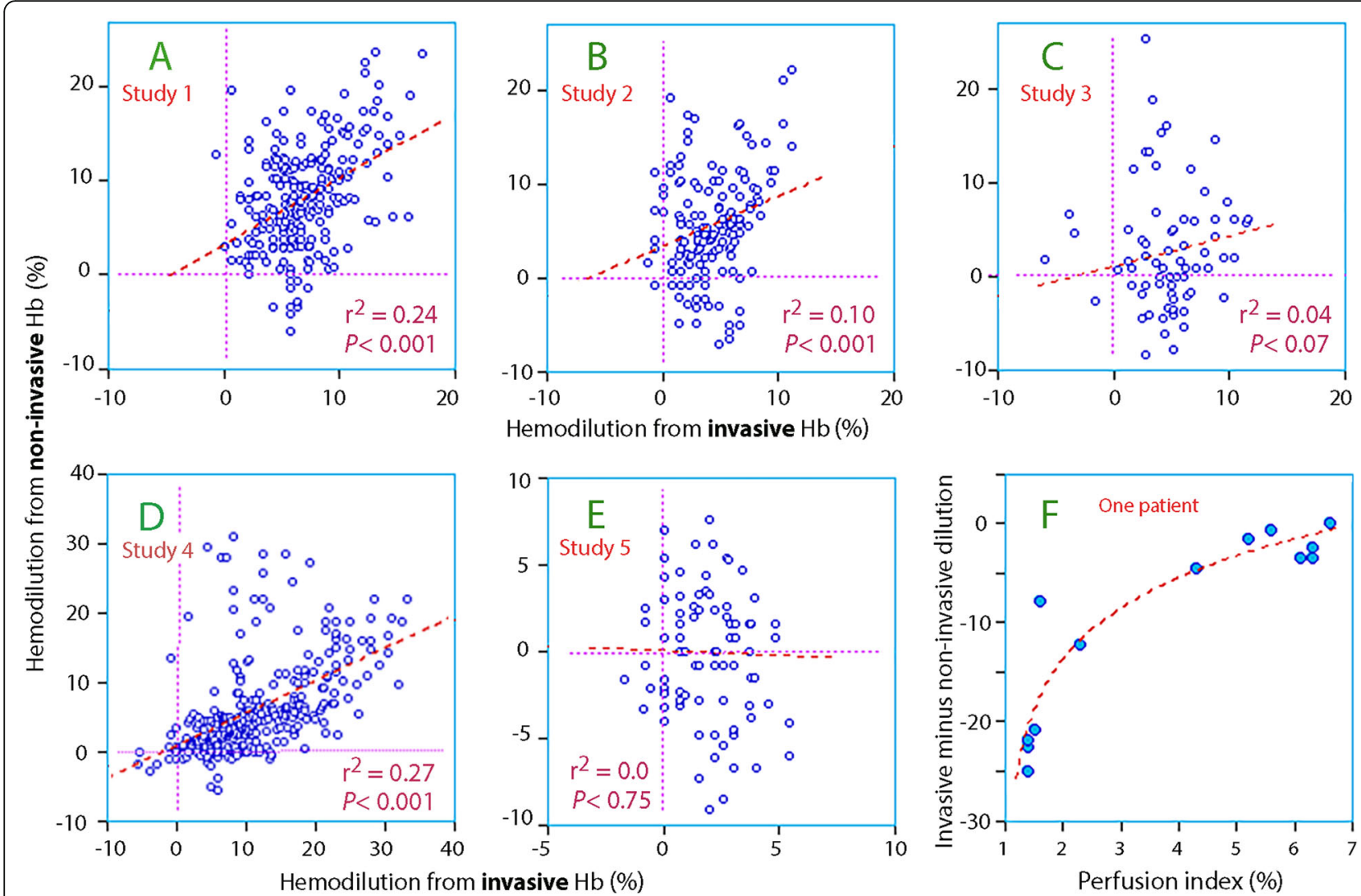

Fig. 3 Relationship between the hemodilution as calculated from the invasive versus the non-invasive Hb measurements in the five studies (a to e) and the correlation between perfusion index and the deviation between the two modes of measuring $\mathrm{Hb}$ in a single patient from Study 4

explained by the combination of higher $k_{12}$ and lower $k_{21}$ (Fig. 6f).

\section{Discussion}

The five evaluated cohorts indicate the possibilities and limits of measuring $\mathrm{Hb}$ non-invasively. Overall, the difference between the highest and lowest $\mathrm{Hb}$ values was quite similar between the two technologies but, as shown many times before, there were wide limits of agreement at the baseline. Nevertheless, changes in $\mathrm{Hb}$ measured by the pulse oximeter often followed quite well the trends yielded by invasive measurement. However, this was not a universal finding. The non-invasive technique showed good precision but underestimated the magnitude of the invasive $\mathrm{Hb}$ changes in the presence of pre-surgical or surgical stress. By contrast, the precision was poor but the accuracy good in the volunteer studies.

\section{Surgical setting versus non-stressed volunteers}

The clinical question of whether erythrocytes should be transfused was most real in Study 4 where measurements were performed during major surgery. The blood loss during the data collection amounted to almost 11 , and the patients received both Ringer's and 20\% albumin. Norepinephrine infusion was used to maintain the arterial pressure. The hemodilution was twice as large as that seen in any of the other studies.

The non-invasive $\mathrm{Hb}$ followed the trends observed in the invasive $\mathrm{Hb}$ quite well, with an overall $\mathrm{r}^{2}$ as high as 0.72 despite occasional outliers that were sometimes due to a low perfusion index. One should note that 0.72 is the mean linearity from individual analysis of each patient, whereas the $\mathrm{r}^{2}$ yielded by point-wise comparisons based on the pooled data from all patients in Study 4 was considerably lower, only 0.27 . Importantly, the magnitude of the hemodilution changes was underestimated, and it usually amounted to only half of the invasive value (Fig. 3d).

The underestimation of the hemodilution by the noninvasive approach is shared by Study 3, which was performed in patients awaiting major open abdominal surgery. The fact that the two clinical studies show the same pattern - namely, a too small hemodilution indicated by the non-invasive $\mathrm{Hb}$ and, hence, a low slope factor - suggests that adrenergic stress limits the magnitude of the $\mathrm{Hb}$ changes detected by the non-invasive technology, albeit without distorting the trend over time. 

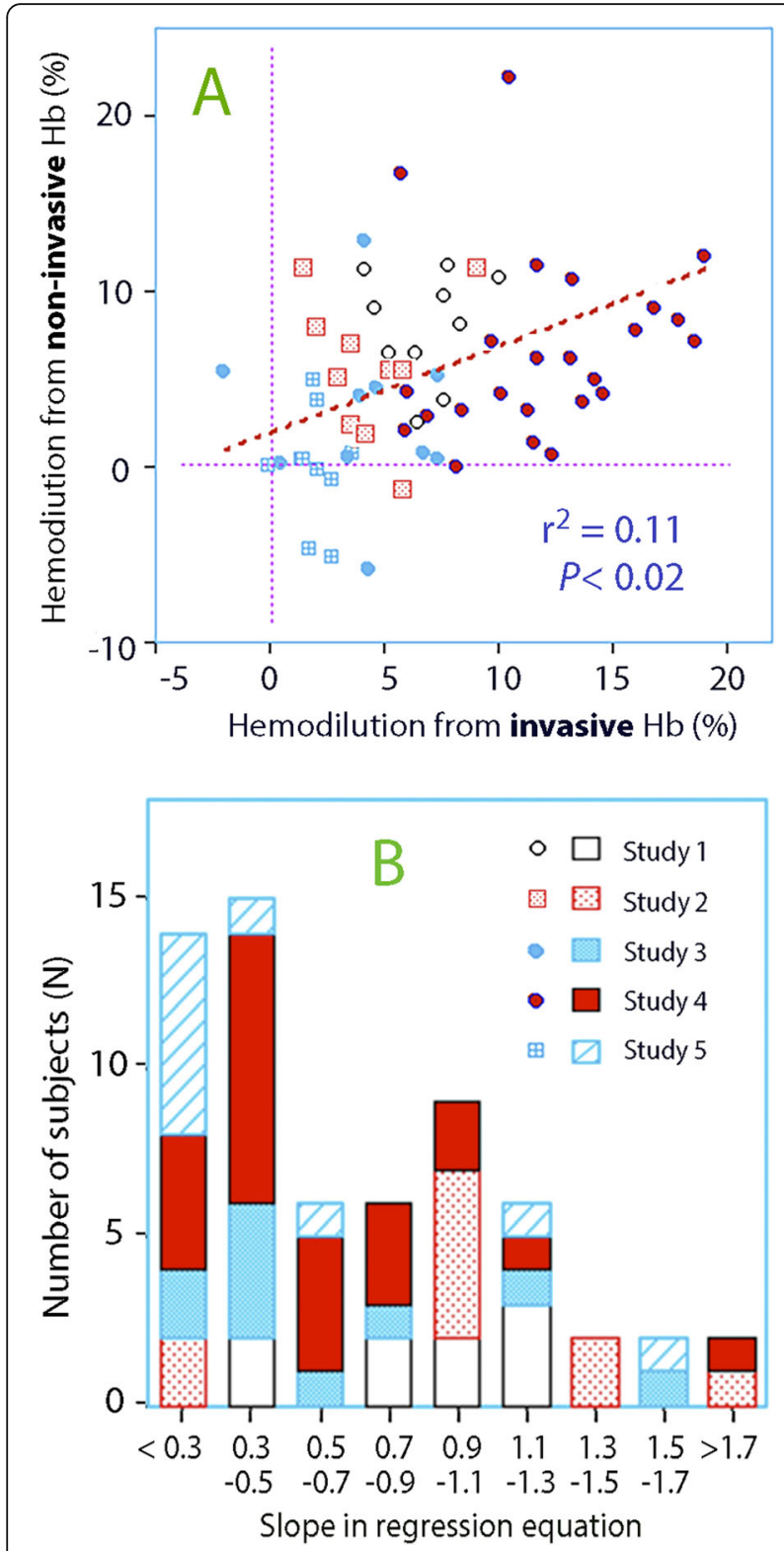

Fig. 4 a Hemodilution as obtained by the invasive $\mathrm{Hb}$ versus the non-invasive $\mathrm{Hb}$ for each patient. $\mathbf{b}$ Distribution of slope factors in the five studies

Studies 1 and 2 were both performed in a similar way in volunteers, but using different amounts of crystalloid fluid. Both studies had slopes with a median value close to 1.0 , and the non-invasive hemodilution was approximately $20 \%$ greater than that obtained with the invasive $\mathrm{Hb}$. Hence, the relationship between the two modes of measurement was opposite to that obtained in the perioperative setting, which supports the notion that data obtained in volunteers cannot be uncritically assumed to be valid in stressful situations.

By contrast, the performance of the non-invasive technology with oral administration of fluid was

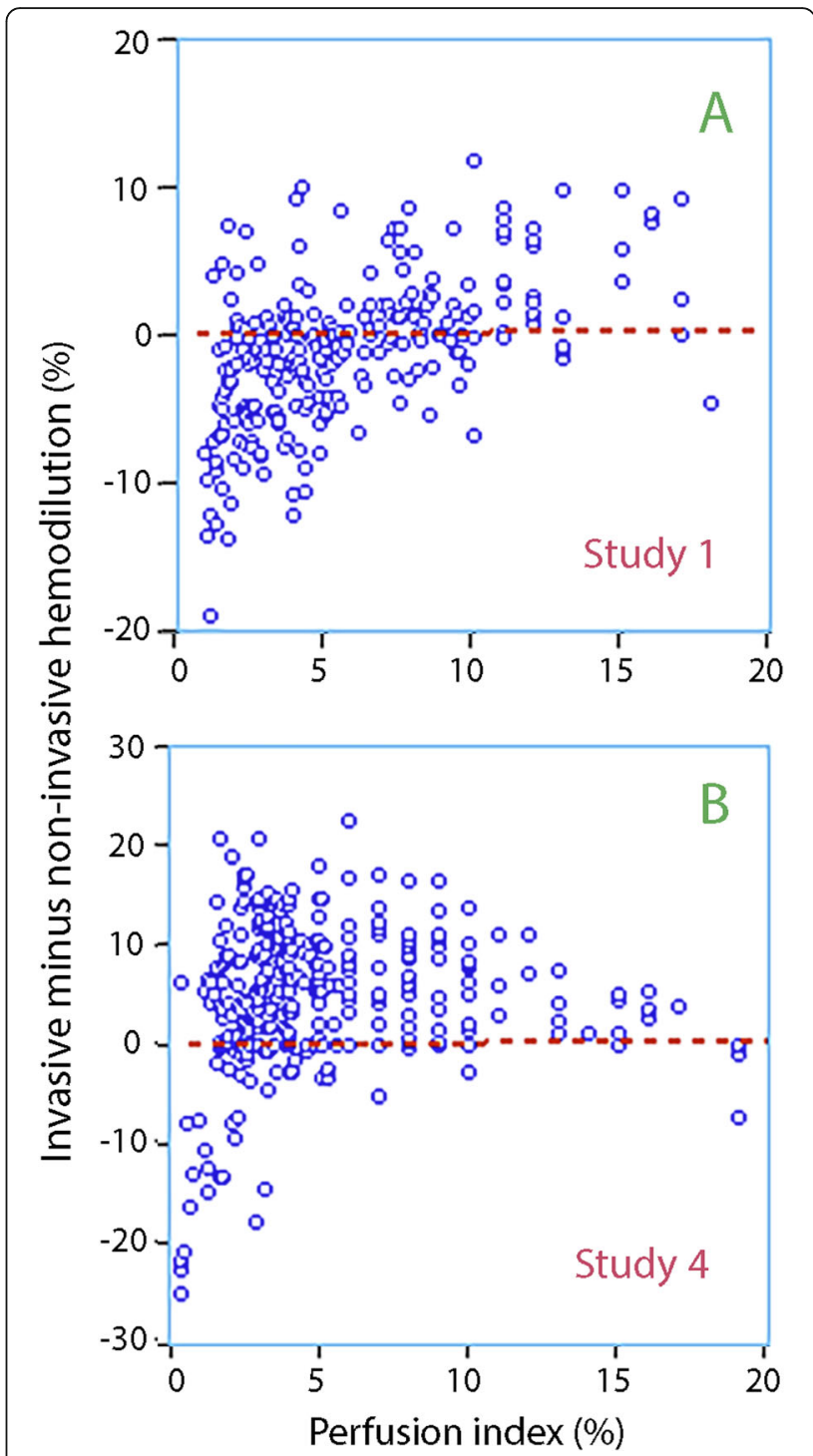

Fig. 5 The perfusion index versus the difference in hemodilution as obtained by the two modes of measuring $\mathrm{Hb}$ in (a) Study 1 and (b) Study 4. These were the only cohorts in which the perfusion index occasionally dropped below 1.0

disappointing. Here, non-invasive measurement usually showed no change at all, or a trend opposite to that obtained by the invasive $\mathrm{Hb}$. However, the average hemodilution obtained by invasive sampling averaged only $3 \%$, which then seems too small to overcome the between-subject variability of the noninvasive $\mathrm{Hb}$ technique to any reasonable degree.

\section{Volume kinetics}

Another issue is whether non-invasive monitoring can be used for the study of fluid population kinetics. For this purpose, the $\mathrm{Hb}$ data had to be converted to plasma dilution, which attains values that are approximately twice as large as the hemodilution. Previous studies have 


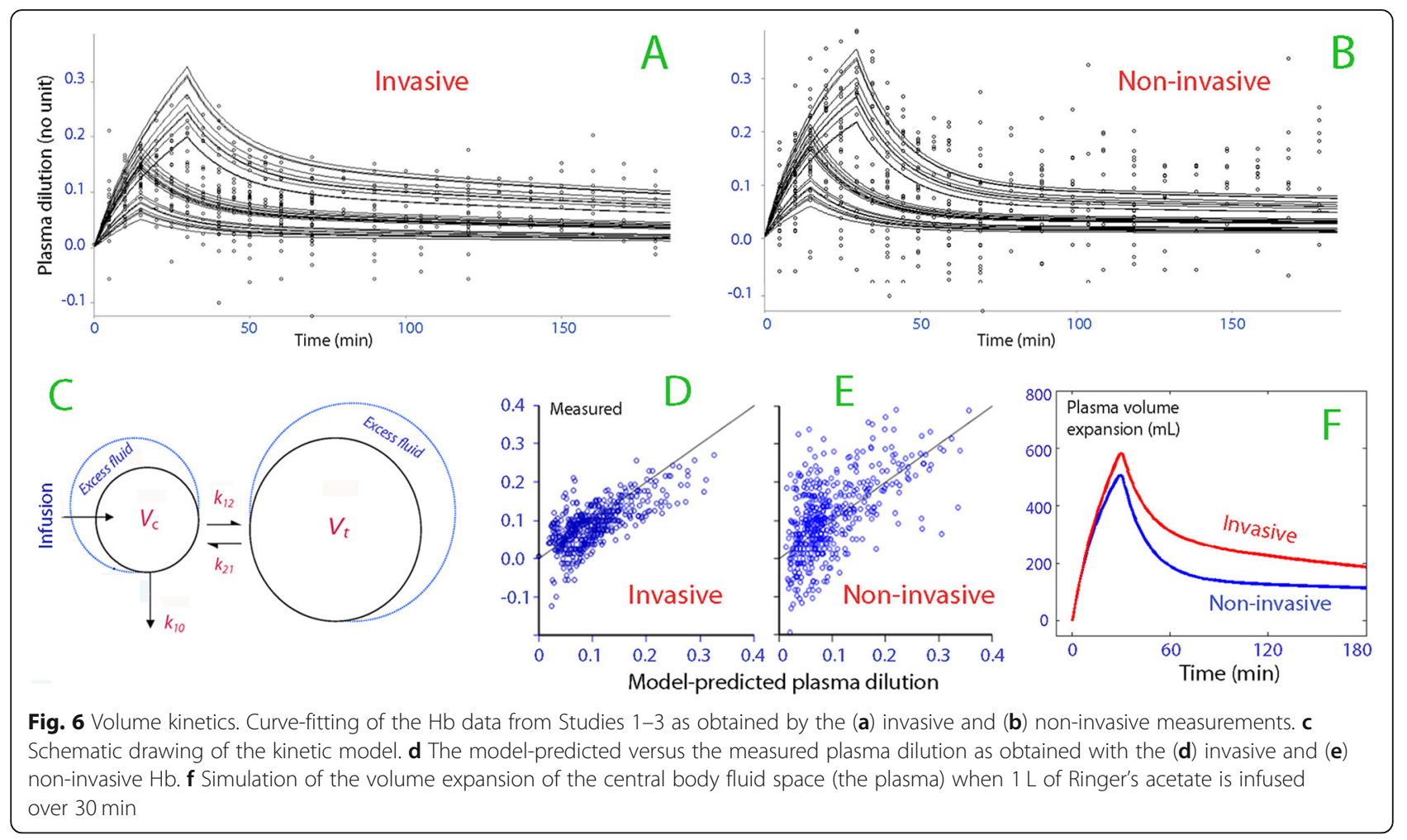

used non-invasive $\mathrm{Hb}$ for kinetic analysis in a two-stage approach, but with limited success [2, 12]. Here, all appropriate curves were analyzed in one single run, which offers a more stable output.

The analysis shown in Fig. 6 reveals that fitting the commonly used two-volume kinetic model to the present data produced more outliers and less precise estimates of the model parameters when based on the non-invasive as compared to the invasive technology. In our fictitious fluid experiment, the difference between the modes of measuring $\mathrm{Hb}$ became apparent during the distribution phase but not during infusion.

\section{Present report versus the literature}

Many previous studies have examined the methodological bias by making point-wise comparisons between invasive and non-invasive measurements of $\mathrm{Hb}$, usually without separating intra- and inter-individual differences. Some studies show a bias of $1-2 \%$ [1-4], while studies in cardiac and emergency care report underestimations of the invasive $\mathrm{Hb}$ of as much as $12-18 \mathrm{~g} \mathrm{~L}^{-1}$ by the non-invasive technique [5-7]. These results support our observation that changes in non-invasive $\mathrm{Hb}$ become too small in stressed settings. The precision has consistently been poor, with $95 \%$ limits of agreement being in the range of $40-50 \mathrm{~g} \mathrm{~L}^{-1}[3,8]$, or even wider [4-7]. The

Table 3 Population kinetic parameters

\begin{tabular}{|c|c|c|c|c|}
\hline Kinetic parameter & Measurement route & Best estimate & $95 \% \mathrm{Cl}$ & CV\% \\
\hline \multirow[t]{2}{*}{$V_{c}(\mathrm{~L})$} & Invasive & 3.91 & $3.27-4.56$ & 8.5 \\
\hline & Non-invasive & 3.11 & $2.51-3.71$ & 9.8 \\
\hline \multirow[t]{2}{*}{$k_{12}\left(10^{-3} \min ^{-1}\right)$} & Invasive & 38.3 & $30.9-46.0$ & 10.0 \\
\hline & Non-invasive & 47.0 & $22.0-72.0$ & 27.1 \\
\hline \multirow[t]{2}{*}{$k_{21}\left(10^{-3} \min ^{-1}\right)$} & Invasive & 23.5 & $14.0-32.9$ & 20.5 \\
\hline & Non-invasive & 11.2 & $(-18.5)-41.0$ & 135.2 \\
\hline \multirow[t]{2}{*}{$k_{10}\left(10^{-3} \mathrm{~min}^{-1}\right)$} & Invasive & 9.1 & $3.7-14.3$ & 29.8 \\
\hline & Non-invasive & 9.4 & $2.7-16.1$ & 36.5 \\
\hline
\end{tabular}


conclusion in a meta-analysis of 32 studies from 2016 confirmed that the mean difference between the two modes of measuring $\mathrm{Hb}$ is small, while the range between the $95 \%$ limits of agreement is too wide to allow clinical decisions to be based on them [1-17].

Our review does not focus on point-wise comparisons; rather, it emphasizes a series of $\mathrm{Hb}$ changes, which we feel is more informative about the value of this monitoring in the perioperative setting. Here, hemodilution curves derived by the two modes of measuring $\mathrm{Hb}$ most often showed quite similar trends, but the many successful cases (high $r^{2}$ ) were occasionally interrupted by curves showing poor agreement, so as to be misleading. Some of these were "switches" remain unexplained. The most stable indications were obtained in the surgical setting, where $r^{2}$ was below 0.25 in only $2 / 23$ patients, although the non-invasive $\mathrm{Hb}$ systematically underestimated the hemodilution. The scattering was aggravated in the presence of a very low perfusion index. By contrast, Chang et al. [10], found the accuracy of the Radical-7 to be good even when the perfusion index is below 1.0.

\section{Limitations}

Limitations of this analysis include that the invasive $\mathrm{Hb}$ was measured in venous blood while the noninvasive method is believed to represent arterial or capillary $\mathrm{Hb}$. However, the two sites of measurement should not differ much in terms of $\mathrm{Hb}$ concentration [18]. The five series of $\mathrm{Hb}$ experiments were collected under different conditions, which are described in detail elsewhere, but these differences do form the basis of the present conclusions [11-16]. Data were collected over a period of almost 10 years, during which the algorithm for calculating non-invasive $\mathrm{Hb}$ is claimed to have been improved. However, more recent work on $\mathrm{Hb}$ during spinal surgery and liver transplantation $[10,19]$ show almost identical accuracy and precision for the non-invasive $\mathrm{Hb}$ as we reported in 2010 [2]. These authors also studied the concordance between changes in invasive and noninvasive $\mathrm{Hb}$ during surgery $[10,19]$. However, we chose to present our results differently, as we obtained data at very short intervals, usually only $5-10$ min, and up to 25 times per experiment.

\section{Conclusions}

Five series of $\mathrm{Hb}$ measurements showed that the linearity between invasive and non-invasive $\mathrm{Hb}$ data was strongest for the most pronounced hemodilution in surgical patients, albeit the hemodilution was underestimated. Data from volunteers yielded better accuracy but showed more scatter (poorer precision). Results were unreliable for hemodilution in the range of $3-4 \%$. The non-invasive methodology has severe limitations, but $\mathrm{Hb}$ trends can be monitored relatively well during surgery to identify the need for erythrocyte transfusion if. However, we recommend that quality of the non-invasive $\mathrm{Hb}$ curve supported by timely invasive measurements.

\section{Abbreviations \\ $\mathrm{Cl}$ : Confidence interval; CV: Coefficient of variation; $\mathrm{Hb}$ : Hemoglobin; $k_{12}$ : Rate constant for fluid passing from the plasma to the extravascular fluid space; $k_{21}$ : Rate constant for fluid passing from the extravascular fluid space to the plasma; $k_{10}$ : Rate constant for fluid leaving the kinetic system as urine; L: Liter; mL: Milliliter; $r^{2}$ : Coefficient of determination ("scatter"); SpHb: Pulse co-oximetry hemoglobin; $V_{c}$ : Size of central body fluid space; $V_{t}$ : Size of peripheral (extravascular) body fluid space}

\section{Supplementary Information}

The online version contains supplementary material available at https://doi. org/10.1186/s12871-021-01351-4

Additional file 1.

\section{Acknowledgements}

The authors are grateful to the co-authors and others who contributed to the original papers on which the present work is based.

Authors' contributions

RGH and JHZ planned the studies but PYW planned Study 4. The data was collected by $\mathrm{JHZ}$ and co-workers and, in Study 4, by PYW. RGH made the calculations and wrote the manuscript. All authors read and approved the final manuscript.

\section{Authors' information}

Robert G. Hahn: Researcher at Södertälje Hospital, Södertälje, Sweden: Professor of Anesthesia and Intensive care at Karolinska Institutet at Danderyds Hospital (KIDS), Stockholm, Sweden.

Patrick Y. Wuethrich: Clinical anesthetist at Inselspital, Bern University Hospital, and associate professor of anesthesia at the University of Bern, Switzerland.

Joachim H. Zdolsek: anesthesiologist at Linköping University Hospital, associate professor at Linköping University, Linköping Sweden.

\section{Funding}

Department funds from Research Unit, Södertälje Hospital. Open Access funding was provided by Karolinska Institutet. The funding organizations played no role in the design, analysis, and interpretation of the data and in writing the manuscript. Open access funding provided by Karolinska Institute.

Availability of data and materials

The data used for the kinetic analysis is available as Additional file.xls (studies 1, 2 and 3). Data for Studies 4 and 5 are available from the corresponding author on request.

\section{Declarations}

\section{Consent to publication}

Not applicable.

Ethics approval and consent to participate

Ethical approvals were obtained by the Regional Ethics Committee of Stockholm, Sweden, as 2009/1091-31/2 (on September 18, 2009); the Regional Ethics Committee of Linköping, Sweden, as M114-09 (June 17, 2009), 2011/101-31 May 20, 2011), and 2010/241-31 September 29, 2010); and by the Cantonal Ethics Committee KEK Bern, Switzerland, KEKBE ID 2018-02351 (on February 20, 2019). The corresponding registrations at ClinicalTrials.gov were NCT01195025, NCT 01062776, NCT01458678, 
NCT01360333, and NCT 03848507. All patients gave us their written informed consent to participate.

\section{Competing interests}

RGH holds a grant from Grifols for the study of $20 \%$ albumin as infusion fluid.

The other authors declare that they have no conflict of interest.

\section{Author details}

${ }^{1}$ Research Unit, Södertälje Hospital, Södertälje, and Karolinska Institutet at Danderyds Hospital (KIDS), Stockholm, Sweden. ${ }^{2}$ Department of Anaesthesiology and Pain Medicine, Inselspital, Bern University Hospital, University of Bern, $\mathrm{CH}-3010$ Berne, Switzerland. ${ }^{3}$ Department of Anesthesiology and Intensive Care, and Department of Medical and Health Sciences, Linköping University, Linköping, Sweden.

Received: 23 September 2020 Accepted: 19 April 2021

Published online: 06 May 2021

\section{References}

1. Macknet MR, Allard M, Applegate RL, Rook J. The accuracy of noninvasive and continuous total hemoglobin measurement by pulse CO-oximetry in human subjects undergoing hemodilution. Anesth Analg. 2010;111(6):14246 https://doi.org/10.1097/ANE.0b013e3181fc74b9.

2. Hahn RG, Li Y, Zdolsek J. Non-invasive monitoring of blood haemoglobin for analysis of fluid volume kinetics. Acta Anaesthesiol Scand. 2010;54(10): 1233-40 https://doi.org/10.1111/j.1399-6576.2010.02321.x.

3. Lamhaut L, Apriotesei R, Combes X, Lejay M, Carli P, Vivien B. Comparison of the accuracy of noninvasive hemoglobin monitoring by spectrophotometry $(\mathrm{SpHb})$ and $\mathrm{HemoCue}^{\circledR}$ with automated laboratory hemoglobin measurement. Anesthesiology. 2011;115(3):548-54 https://doi.org/10.1097/A LN.0b013e3182270c22

4. Miller RD, Ward TA, Shiboski SC, Cohen NH. A comparison of three methods of hemoglobin monitoring in patients undergoing spine surgery. Anesth Analg. 2011;112(4):858-63 https://doi.org/10.1213/ANE.0b013e31820eecd1.

5. Colquhoun DA, Forkin KT, Durieux ME, Thiele RH. Ability of the Masimo pulse CO-oximeter to detect changes in hemoglobin. J Clin Monit Comput. 2012;26(2):69-73 https://doi.org/10.1007/s10877-012-9335-3.

6. Nguyen B-V, Vincent J-L, Nowak E, Coat M, Paleiron N, Gouny P, et al. The accuracy of noninvasive hemoglobin measurement by multiwavelength pulse oximetry after cardiac surgery. Anesth Analg. 2011;113(5):1052-7 https://doi.org/10.1213/ANE.0b013e31822c9679.

7. Gayat E, Bodin A, Sportiello C, Boisson M, Dreyfus JF, Mathieu E, et al. Performance evaluation of a noninvasive hemoglobin monitoring device. Ann Emerg Med. 2011;57(4):330-3 https://doi.org/10.1016/j.a nnemergmed.2010.11.032.

8. Causey MW, Miller S, Foster A, Beekley A, Zenger D, Martin M. Validation of noninvasive hemoglobin measurements using the Masimo Radical-7 SpHb Station. Am J Surg. 2011;201(5):592-8 https://doi.org/1 0.1016/j.amjsurg.2011.01.020.

9. Berkow L, Rotolo S, Mirski E. Continuous noninvasive hemoglobin monitoring during complex spine surgery. Anesth Analg. 2011;113(6):1396402 https://doi.org/10.1213/ANE.0b013e318230b425.

10. Chang FC, Lin JR, Liu FC. Validity of accuracy and trending ability of noninvasive continuous total hemoglobin measurement in complex spine surgery: a prospective cohort study. BMC Anesthesiol. 2019;19(1):117. https://doi.org/10.1186/s12871-019-0790-y.

11. Hahn RG, Bergek C, Gebäck T, Zdolsek J. Interactions between the volume effects of hydroxyethyl starch 130/0.4 and Ringer's acetate. Crit Care. 2013; 17(3):R104 https://doi.org/10.1186/cc12749.

12. Zdolsek J, Li Y, Hahn RG. Detection of dehydration by using volume kinetics. Anesth Analg. 2012;115(4):814-22. https://doi.org/ANE.0b013e3182 61f6ba. https://doi.org/10.1213/ANE.0b013e318261f6ba.

13. Hahn RG, Bahlmann H, Nilsson L. Dehydration and fluid volume kinetics before major open abdominal surgery. Acta Anaesthesiol Scand. 2014; 58(10):1258-66. https://doi.org/aas.12416. https://doi.org/10.1111/aas.12416.

14. Löffel LM, Hahn RG, Engel D, Wuethrich PY. Intraoperative intravascular effect of ringer lactated and hyperoncotic albumin during hemorrhage in cystectomy patients. Anesth Analg. 2020; https://doi.org/10.1213/ane. 0000000000005173, Publish Ahead of Print.
15. Zdolsek J, Metander AS, Hahn R. Volume kinetic evaluation of fluid turnover after oral intake of tap water, lemonade and saline in volunteers. BMC Sports Sci Med Rehabil. 2016;8(1):22. https://doi.org/1 0.1186/s13102-016-0045-x

16. Bergek C, Zdolsek JH, Hahn RG. Accuracy of non-invasive hemoglobin $(\mathrm{SpHb})$ depends on the type of infusion fluid. Eur J Anaesthesiol. 2012; 29(12):586-92 https://doi.org/10.1097/EJA.0b013e3283592733.

17. Kim SH, Lilot M, Murphy LS, Sidhu KS, Yu Z, Rinehart J, et al. Accuracy of continuous noninvasive hemoglobin monitoring. Anesth Analg. 2016;119(2): 332-46 https://doi.org/10.1213/ANE.0000000000000272.

18. Hahn RG, Lindahl C, Drobin D. Volume kinetics of acetated Ringer's solution during experimental spinal anaesthesia. Acta Anaesthesiol Scand. 2011;55(8): 987-94 https://doi.org/10.1011/j.1399-6576.2011.02493.x.

19. Huang PH, Shih BF, Tsai YF, Chung PCH, Liu FC, Yu HP, et al. Accuracy and trending of continuous noninvasive hemoglobin monitoring in patients undergoing liver transplantation. Transpl Proc. 2016;48(4):1067-70 https:// doi.org/10.1016/j.transproceed.2015.12.121.

\section{Publisher's Note}

Springer Nature remains neutral with regard to jurisdictional claims in published maps and institutional affiliations.

Ready to submit your research? Choose BMC and benefit from:

- fast, convenient online submission

- thorough peer review by experienced researchers in your field

- rapid publication on acceptance

- support for research data, including large and complex data types

- gold Open Access which fosters wider collaboration and increased citations

- maximum visibility for your research: over $100 \mathrm{M}$ website views per year

At BMC, research is always in progress.

Learn more biomedcentral.com/submissions 